\title{
A Reduced Multicomponent Diffusion Model
}

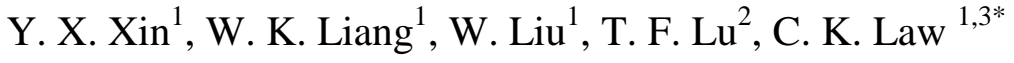 \\ ${ }^{1}$ Department of Mechanical and Aerospace Engineering \\ Princeton University, Princeton, NJ 08544, USA \\ ${ }^{2}$ Department of Mechanical Engineering \\ University of Connecticut, Storrs, CT 06269, USA \\ ${ }^{3}$ Center for Combustion Energy \\ Tsinghua University, Beijing 100084, China
}

\begin{abstract}
The diffusion models for multicomponent mixtures are investigated in planar premixed flames, counterflow diffusion flames, and ignition of droplet flames. Discernable discrepancies were observed in the simulated flames with the mixture-averaged and multicomponent diffusion models, respectively, while the computational cost of the multicomponent model is significantly higher than that of the mixture-averaged model. A systematic strategy is proposed to reduce the cost of the multicomponent diffusion model by accurately accounting for the species whose diffusivity is important to the global responses of the combustion systems, and approximating those of less importance. The important species in the reduced model are identified with sensitivity analysis, and are found to be typically among those in high concentrations with exception of a few radicals, e.g. $\mathrm{H}$ and $\mathrm{OH}$, that are known to participate in critical reactions. The reduced model is validated in simulating the propagation of planar premixed flames, extinction of counterflow non-premixed flames and ignition of droplet flames. The reduced model was shown to feature similar accuracy to that of the multicomponent model while the computational cost was reduced by a factor of approximately 5 for an $n$-heptane mechanism with 88 species.
\end{abstract}

Keyword: multicomponent diffusion, diffusion model, model reduction

\footnotetext{
* Corresponding author, email: cklaw@princeton.edu
} 


\section{Introduction}

Accurate modeling of diffusion is essential in the simulation of the structure and response of flames, which consist of a multitude of chemical species strongly interacting with each other in narrow spatial domains of steep concentration gradients The task is monumental as the diffusion of a single species would depend on the properties and concentrations of all the species in the mixture. For a mixture of $N$ perfect gas components, the Maxwell-Stefan multicomponent diffusion model, is derived from the Boltzmann's equation of kinetic theory [1-11] and recently revisited by Lam [12], offers the most rigorous, state-of-the-art description for combustion simulations. Its implementation, however, incurs significant computational cost due to the required matrix inversion, particularly when large reaction mechanisms are involved. As such, it is difficult to employ the multicomponent model in large-scale flame simulations. A simplified description is that of Curtiss and Hirschfelder [1], who obtained the solution to the first-order perturbations of the Boltzmann equation following the Chapman-Cowling procedure [3], and developed a mixture-averaged diffusion model to describe the diffusion of species in low concentrations. For many combustion systems, the mixture-averaged model offers rather good accuracy with substantially lower computational cost, and thus has long been the de facto standard in combustion simulations as reviewed by Smooke [13]. The multicomponent model is typically needed in such special situations when the Soret effect is of interest, for non-dilute mixtures or when high accuracy is required [14-23]. 
The effects of using the mixture-averaged vs. the multicomponent model on flame simulations have been extensively studied. For example, Bongers et al. [18] examined the laminar planar premixed flames for $\mathrm{H}_{2}-$ air, $\mathrm{H}_{2}-\mathrm{O}_{2}$ and $\mathrm{CH}_{4}$-air, showing that the differences between the two models are discernable in predicting the flame speed. Gopalakrishnan et al. [19] investigated the ignition of $n$-heptane-air diffusion flames, and reported a $10 \%$ difference in the transient temperature and major species profiles. Dworkin et al. [24] studied soot formation in $\mathrm{C}_{2} \mathrm{H}_{4}$-air counterflow and coflow flames, and found that although the different diffusion models induce only small differences in the temperature profiles, they could lead to $10 \%-15 \%$ deviation in the peak soot volume fraction. For premixed turbulent flames, Charentenay et al. [25] simulated the interaction of $\mathrm{H}_{2}-\mathrm{O}_{2}$ flames with turbulence, and found that the two models result in rather different instantaneous profiles of temperature and species concentrations, especially for highly curved flames. However, turbulence fluctuations appear to diminish these effects when considering the mean quantities, leading to a rather small change of $7 \%$ in the thickness of the flame brush. Kumar et al. [26] studied the heterogeneous combustion of $\mathrm{H}_{2}$-air and $\mathrm{CH}_{4}$-air mixtures in a monolithic channel coated by platinum, and found a $2 \%$ difference in the fuel concentrations at the exit of the channel. It is also noteworthy that Giovangigli and Ern $[14-15,27]$ reduced the cost of the Maxwell-Stefan model from the mathematic point of view. They developed the iterative methods for solving the Maxwell-Stefan model. All transport coefficients are expressed as convergent series and approximated by the truncation of these series, as implemented in the EGLIB software package [28]. 
The objective of the present study is to develop a systematic approach to reduce the cost of the multicomponent model, hereafter referred to as the reduced multicomponent (RM) model, based on the physical understanding of the combustion systems. Its efficiency and fidelity is demonstrated for mixtures of $n$-heptane-air. Results show that the RM model retains the high accuracy of the multicomponent model and features a computational cost linearly proportional to the number of species.

\section{Comparison of the Diffusion Models in Combustion Simulations}

\subsection{Simulation configuration}

To compare the mixture-averaged and multicomponent models in different flames, three combustion systems of heptane-air mixture, namely the planar premixed flame, the counterflow diffusion flame and ignition of the droplet flame, are simulated, covering premixed and non-premixed, stretched and unstretched, and steady and unsteady conditions. The planar premixed flame and counterflow diffusion flame are simulated by using the algorithms of Kee et al. [29] and Nishioka et al. [30], respectively, while ignition of the droplet flame is simulated with the Adaptive Simulation of Unsteady Reacting Flows (A-SURF) code [31-35]. The chemistry of heptane oxidation is described by a skeletal mechanism of 88 species [36] derived from a detailed mechanism [37], which is available online [38]. 
The planar premixed flame is simulated over the range of parameters with equivalence ratios of 0.6 to 1.5 , pressure of 1 to 40 atm, and freestream temperature of 300K. Simulation of the counterflow diffusion flame is conducted for pure heptane against air with temperature of $300 \mathrm{~K}$ at both inlets, and pressure of 1 to $3 \mathrm{~atm}$. Such parameters are selected to match the operation conditions of the flame speed measurement in [39] and the counterflow flame experiment in [40]. Each simulation starts with coarse grids and the mixture-averaged model. The grid is then refined iteratively until the solution converges. The diffusion model is then switched to the multicomponent model while the mesh is fixed, such that comparison of the models will not be biased due to changes in the mesh. For the unsteady droplet ignition, the droplet has initial radius of $1 \mathrm{~mm}$ and uniform temperature of $300 \mathrm{~K}$. The ambient air is quiescent at temperature of $1400 \mathrm{~K}$ and pressure of $40 \mathrm{~atm}$, being relevant to the working condition of IC engines [41]. The initial boundary layer at the surface of the droplet spans approximately 100 grid points, with temperature and species concentrations linearly interpolated from the droplet surface condition to the ambient condition. The evolution of the system is simulated by solving the 1-D, unsteady, compressible $N-S$ equations, species equations and energy equation for the multicomponent reacting flow in the spherical coordinate. Thermal diffusion is not considered in all the simulations. 


\subsection{Simulation results with different diffusion models}

Figure 1 presents the relative error of the mixture-averaged model in predicting the burning flux of the laminar premixed flame, $f^{0}$, as a function of equivalence ratio, $\phi$, under different pressures. The relative error is $0.5 \%-1 \%$ at atmospheric pressure, and increases to $2 \%$ at 40 atm. Compared with the typical uncertainty of $5 \%$ in experimental measurements of the flame speed [39], the mixture-averaged model results in only a minor deviation for the planar premixed flame.

Figure 2 illustrates the maximum temperature, $T_{\max }$, in counterflow flames of pure heptane against air as a function of strain rate, $\kappa$, at pressures of $1-3 \mathrm{~atm}$. It is seen that the extinction strain rates at the turning points predicted by the mixture-averaged and multicomponent models differ by $4 \%$ at atmospheric pressure and $6 \%$ at elevated pressures. Consequently, the counterflow diffusion flame is more sensitive to the selection of the diffusion model as compared to the premixed flame, in Fig. 1. Furthermore, based on the results in Figs. 1-2, deviation of the mixture-averaged model tends to increase at higher pressures.

In the simulation of unsteady droplet ignition, the fuel and air are mixed within a thin layer near the droplet surface through diffusion. Radicals build up during the induction period until approximately $t=20 \mathrm{~ms}$, when thermal runaway is triggered. From 20 to $28 \mathrm{~ms}$, the maximum system temperature rapidly increases from 1500 to $2900 \mathrm{~K}$ before a steady diffusion flame is established. The overall progress of the ignition is indicated by the evolution of the maximum temperature as shown in Fig. 3 
(upper panel), together with the relative errors of the mixture-averaged model (lower panel) in the maximum $\mathrm{H}$ mole fraction. Although the mixture-averaged model under-predicts the ignition delay by merely $20 \mu$ s, the intensive unsteadiness amplifies its deviation in the maximum mole fraction of $\mathrm{H}$ radical to approximately $10 \%$ at $24 \mathrm{~ms}$ near the inflection point on the temperature profile, which is widely accepted as the ignition point. Based on the above observations, the mixture-averaged model may result in discernable deviations, say about $10 \%$, in flame simulations and the multicomponent model is needed if higher accuracy is required.

\section{Methodology for Multicomponent Diffusion Reduction}

\subsection{Review of the multicomponent diffusion model}

For a mixture of $N$ ideal gas components, the diffusion velocity of the $i^{\text {th }}$ species, $\mathbf{v}_{i}$, is formulated by the multicomponent model [12] as

$$
\begin{aligned}
& \mathbf{v}_{i}=-\sum_{j=1}^{N} D_{i j}^{M u l} \mathbf{d}_{j}+D_{i}^{T} \nabla \ln T \\
& \mathbf{d}_{i}=\nabla X_{i}+\left(X_{i}-Y_{i}\right) \nabla p+\mathbf{g}_{i} \\
& \mathbf{g}_{i}=\frac{\rho Y_{i}}{p} \sum_{k=1}^{N} Y_{k}\left(\mathbf{f}_{k}-\mathbf{f}_{i}\right)
\end{aligned}
$$

where $D_{i j}^{M u l}$ is the multicomponent diffusion coefficient of species $i$ with respect to $j$, $D_{i}^{T}$ the thermal diffusion coefficient of species $i, X_{i}$ and $Y_{i}$ the mole and mass fractions of species $i$, respectively, $p$ the pressure, $\rho$ the density, and $\mathbf{f}_{k}$ the specific 
body force acted on the $k^{\text {th }}$ species. The thermal diffusion of the species is neglected in the present study, i.e. $D_{i}^{T}=0 \forall i$.

The major cost of the multicomponent model is the calculation of the $D_{i j}^{M u l}$ term, given by the inverse of the diffusion matrix $L[42]$ as

$$
\begin{aligned}
& D_{i j}^{M u l}=X_{\mathrm{i}} \frac{16 T \bar{m}}{25 p m_{j}}\left(L_{i j}^{-1}-L_{i i}^{-1}\right) \\
& L_{s t}=\frac{16 T}{25 p} \sum_{k=1}^{N} \frac{X_{k}}{m_{s} D_{s k}^{*}}\left\{m_{t} X_{t}\left(1-\delta_{s k}\right)-m_{s} X_{t}\left(\delta_{s t}-\delta_{t k}\right)\right\}
\end{aligned}
$$

where $m_{j}$ is the molecular weight of species $j, \bar{m}$ the average molecular weight of the mixture, $D_{i k}^{*}$ the binary diffusion coefficient of species $i$ with respect to $k$, and $\delta_{i j}$ the Kronecker delta. In the CHEMKIN transport library [42], $L^{-1}$ is solved by the LAPACK package [43] with LU factorization, the cost of which scales as a cubic function of the matrix size.

\subsection{A reduced multicomponent diffusion model}

To reduce the cost of the multicomponent model, a reduced model is proposed based on the observation that global responses of combustion systems are sensitive only to the diffusivities of a subset of the species, referred to as the critical-diffusivity-species (CDS) hereafter. Correspondingly, other species are referred to as the non-critical diffusive species (NCDS). In the reduced model, the 
diffusion velocities of CDS are computed with the multicomponent model, while those of NCDS are computed with the less expensive mixture-averaged model:

$$
\begin{aligned}
& \text { If } \quad i \in \mathrm{CDS} \quad \mathbf{v}_{i}=-\sum_{j=1}^{N} D_{i j}^{R m u l} \mathbf{d}_{j} \\
& \text { If } i \in \operatorname{NCDS} \quad \mathbf{v}_{i}=-\frac{1}{X_{i}} D_{i}^{M i x} \mathbf{d}_{i} \\
& \forall j \in \mathrm{NCDS} \\
& D_{i j}^{R m u l}=X_{i} \frac{16 T \bar{m}}{25 p m}\left(L R_{i j}^{-1}-L R_{i i}^{-1}\right) \\
& L R_{s t}=\frac{16 T}{25 p} \sum_{k=1}^{M+1} \frac{X_{k}}{m_{s} D_{s k}^{*}}\left\{m_{t} X_{t}\left(1-\delta_{s k}\right)-m_{s} X_{t}\left(\delta_{s t}-\delta_{t k}\right)\right\}
\end{aligned}
$$

where $D_{i j}^{R m u l}$ is the reduced multicomponent diffusion coefficient of species $i$ with respect to $j, D_{i}^{M i x}$ is diffusion coefficient of species $i$ calculated with the mixture-averaged model, and $M$ is the total number of CDS. For each NCDS $j$, a sub-system is formed by including all $\mathrm{CDS}$ and $j$, referred to as the reduced multicomponent system. The multicomponent model is applied to the reduced multicomponent system characterized by the reduced diffusion matrix, $L R$, and the reduced multicomponent diffusion coefficients, $D_{i j}^{R m u l}$, computed from the inverse of $L R$. The cost for each NCDS scales as a cubic function of the dimension of the matrix $L R$ associated with it, i.e. $O\left((\mathrm{M}+1)^{3}\right)$. Since the similar routine is repeated for every NCDS, for a total of $N-M$ times, the total cost for evaluation of the reduced multicomponent model is proportional to $(N-M)(M+1)^{3}$. Note that the cost for the inversions of the diffusion matrices in the detailed models is $O\left(N^{3}\right)$, significant 
savings can be achieved by breaking the inversion of a large matrix into a set of smaller ones, particularly when $M \ll N$.

While the time saving of the reduced model only depends on $M$, the accuracy also depends on specific selections of the $M$ CDS. A good CDS candidate is expected to be in sufficiently large concentration to have significant effects on the diffusion coefficients, since the diffusion of a species is dominated by its collisions with species in high concentrations. In addition, a radical may also be CDS if it participates in crucial reactions, e.g. $\mathrm{H}$ and $\mathrm{OH}$. The mass diffusion of these radicals can modify the profiles of their concentration, and subsequently changing the reaction rates.

\subsection{Species bundling for further reduction}

In a multicomponent system, such species as isomers may have similar molecular properties and thus similar diffusivities, and can be bundled for diffusivity evaluation. Such species are referred to as similar-diffusivity-species (SDS). Species bundling has been implemented for the binary diffusion coefficients and applied in the reduction of the mixture-averaged model [44], and it is extended to the multicomponent diffusion model in the present work. Based on Eq. (2), the $j^{\text {th }}$ column vector of the diffusion matrix, $\boldsymbol{L}_{j}$, describes the diffusion of other species with respect to the $j$ th species. If the $j t h$ and $j$ 'th species are SDS, all the other species have similar diffusivities with respect to them. i.e. the difference in their corresponding column vectors must be small compared with a threshold value $\varepsilon_{G}$. 


$$
\max \left(\frac{L_{i j}-L_{i j^{\prime}}}{L_{i j}+L_{i j^{\prime}}}\right) \quad<\varepsilon_{G} \quad \forall i \in \operatorname{CDS} \quad i \neq j, j^{\prime}
$$

\subsection{Correction of the diffusive velocity}

Since the RM model is a hybrid of the multicomponent model and the mixture-averaged model, it does not guarantee that the net species diffusion flux is zero. As such, the net diffusive velocity computed with Eq. (3) needs to be corrected to ensure mass conservation, following the approach in the mixture-averaged model in the CHEMKIN transport library [44]. In the present work, a constant correction velocity $\mathbf{V}_{c}$ recommended by Coffee and Heimerl [45] is adopted:

$$
\mathbf{V}_{c}=\sum_{i=1}^{N} \mathbf{v}_{i} Y_{i}
$$

Note that, although mass conservation can be theoretically guaranteed in the multicomponent model, corrections are still performed in practical simulation due to numerical errors.

\section{Implementation of RM Model in Heptane-Air Flames}

Following the strategy in Section 3.2, construction of the RM model starts with identifying CDS and SDS by using the procedure in Section 4.1. The analysis is based on the simulation results of the planar premixed flame and the counterflow diffusion 
flame for heptane-air mixtures, covering the parameter space studied in Section 2. The RM model is then validated and discussed in Section 4.2.

\subsection{Identification of the Reduced Multicomponent Model}

The first step in the reduction of the multicomponent model is to identify the CDS through sensitivity analysis, with the sensitivity coefficient defined as

$$
s_{i}=\left|\frac{\partial \ln \psi}{\partial \ln \left(D_{i}^{M i x}\right)}\right|
$$

where $\psi$ is a global flame parameter, such as the flame speed and the extinction strain rate of the counterflow diffusion flame. The sensitivity coefficient $s_{i}$ can be calculated through numerical perturbations. Figure 4 illustrates the sensitive coefficients computed from the planar premixed flame of stoichiometric heptane-air at $40 \mathrm{~atm}$. It is seen that the sensitivity of the species rapidly decays with the species index. Note that the sensitivity coefficients are shown in logarithmic scale. The top 10 species are $\mathrm{O}_{2}, \mathrm{H}, n-\mathrm{C}_{7} \mathrm{H}_{16}, \mathrm{C}_{2} \mathrm{H}_{4}, \mathrm{~N}_{2}, \mathrm{H}_{2} \mathrm{O}, \mathrm{H}_{2}, \mathrm{CO}_{2}, \mathrm{CO}$, and $\mathrm{OH}$. The same species ranking is also identified in other simulations. Figure 4 also shows the maximum mole fraction of species, $x_{\max }$, across the domain in the same sequence as that in the upper panel. The top $10 \mathrm{CDS}$ other than $\mathrm{H}$ and $\mathrm{OH}$ completely overlap with species of the largest $x_{\max }$, suggesting that CDS tend to be in high concentrations. To identify species featuring overall large concentrations across a flame, the species 
concentrations are sorted on each grid point and the minimum set of species from the top of the list, which account for at least $97 \%$ of the mole fraction in total, are retained for this local grid. The union of all the retained species at each grid then constitutes the set of high-concentration species in the present study. The identified set includes 8 species: $\mathrm{N}_{2}, n-\mathrm{C}_{7} \mathrm{H}_{16}, \mathrm{O}_{2}, \mathrm{H}_{2} \mathrm{O}, \mathrm{CO}, \mathrm{CO}_{2}, \mathrm{H}_{2}$, and $\mathrm{C}_{2} \mathrm{H}_{4}$, as indicated by their $x_{\max }$. The same result is also obtained in other simulations. Figure 4 therefore verifies the hypothesis in Section 3.2: the combustion system is only sensitive to the diffusivity of a subset of species, which are typically either in high concentrations or are highly reactive radicals such as $\mathrm{H}$ and $\mathrm{OH}$.

Based on the above analysis, an alternative approach to construct the set of CDS is proposed to simplify the procedure described above. Procedurally, the CDS in the RM model can be created by merging the high-concentration species with a few important radicals, e.g. $\mathrm{H}$ and $\mathrm{OH}$. Moreover, the set of CDS, identified in this work, shows weak dependence on the type of hydrocarbon fuels and it primarily consists of small molecules. This observation highly suggests that the dimension of RM model is primarily determined by the number of high-concentration species, and roughly remains a constant regardless of the complexity of fuel molecules. To support this statement, planar premixed flames are simulated for stoichiometric mixtures of different hydrocarbons and air at 40 atm, using the detailed mechanism JetSurF 2.0 [46]. The fuels include $n$-alkanes from heptane to dodecane, 1 -alkene from heptene to dodecene and methyl-cyclohexane. The same set of eight high-concentration species 
have been identified in all the cases. Therefore, when the RM model is applied for the complex fuel molecules with large mechanisms of an increasing size $N$, its size, $M$, is expected to be invariant while its computational cost, $O\left((N-M)(M+1)^{3}\right)$, should linearly scale with the size of the mechanism.

The second step of the RM model is to identify the SDS by comparing the column vectors of the diffusion matrix $L$ from Eq. (4). Figure 5 correlates the number of SDS, $N_{\mathrm{SDS}}$, with the species grouping threshold, $\varepsilon_{G}$. Thirty-two species are identified as SDS for $\varepsilon_{G}<1 \mathrm{E}-4$, and they correspond to the isomers in the system. When $\varepsilon_{G}$ is larger than 7E-4, the number of SDS increases rapidly by including non-isomeric species, leading to significant deviation in the simulation results. It is found that simulation of the counterflow diffusion flame can fail to converge when $\varepsilon_{G}>8 \mathrm{E}-4$, and at most 37 SDS are bundled into 10 groups as displayed in Table 1. No CDS is identified as SDS in such cases, and 78 NCDS are bundled into 51 groups, reducing the cost of the reduced multicomponent model from $O\left((N-M)(M+1)^{3}\right)$ to $O$ $\left(N_{g}(M+1)^{3}\right)$, where $N_{\mathrm{g}}$ is the number of bundled species groups.

\subsection{Validation of the Reduced Multicomponent Model}

For heptane-air mixtures, the RM model is validated in simulating the burning flux of planar premixed flames, the extinction strain rate of counterflow diffusion flames and the evolution of the maximum $\mathrm{H}$ radical mole fraction during droplet ignition. Figures (6)-(8) compare the accuracy of the different diffusion models. In all 
cases, the RM model agrees well with the multicomponent model. The error in the reduced multicomponent model is smaller than that of the mixture-averaged model by about an order of magnitude, while the SDS bundling step also does not induce any significant error in addition.

The computational cost of the different diffusion models is illustrated in Fig. 9. While the assessment is based on the planar premixed flame of the stoichiometric heptane-air at $40 \mathrm{~atm}$, the cost is not sensitive to the flame configuration for fixed $M$ and $N$ values. For each evaluation of the diffusion coefficients, the computational time of multicomponent model, the reduced model without bundled species, the reduced model with bundled species and the mixture-averaged model are $2.03 \mathrm{~s}, 0.40 \mathrm{~s}, 0.26 \mathrm{~s}$ and $0.11 \mathrm{~s}$, respectively. It is seen that the reduced model without bundled species saves $80 \%$ computational time compared to the multicomponent model, , and is mostly consistent with the estimation based on the cost to invert the matrices, $(N-M)(M+1)^{3} / N^{3} \approx 15 \%$, for the current model with 10 CDS species. The extra $5 \%$ of the cost is attributed to the overhead of reduced multicomponent model, e.g. assembling the diffusion matrices of the multiple reduced multicomponent systems. The strategy of bundling SDS introduces additional 35\% saving, proportional to $N_{g} /(N-M) \approx 65 \%$ for $N_{g}=51$. The reduced multicomponent model with bundled SDS requires 2.5 times computational cost as that of the mixture-averaged model.

To further investigate the dependence of accuracy and efficiency of the RM model on the model size, planar premixed flames for stoichiometric heptane-air at 40 atm are simulated with different numbers of CDS, with SDS bundling disabled. The 
results are shown in Fig. 10. It is noted that the CDS are sequentially added to the reduce models based on the species ranking in the upper panel of Fig. 4. The minimal RM model in the simulations contains three CDS, namely $n-\mathrm{C}_{7} \mathrm{H}_{16}, \mathrm{O}_{2}, \mathrm{~N}_{2}$, and it shows similar accuracy and computational cost compared to the mixture-averaged model, with the relative error being about $1 \%$ and the computational time being $0.13 \mathrm{~s}$ per iteration. It is seen that the model accuracy increases with the model size and reaches a plateau for more than 10 species, which justifies the truncation at $10 \mathrm{CDS}$ species in the present study. Furthermore, the cost of the RM model peaks around 65 species, corresponding to the maximum value of function $(N-M)(M+1)^{3}$, achieved at $M \approx 0.75 N$. The maximum cost is about ten times that of the multicomponent model. As such, computational savings can only be achieved by using the reduced model when $M$ is significantly smaller than $N$.

\section{Concluding Remarks}

The mixture-averaged and the Maxwell-Stefan multicomponent diffusion models are compared in flame simulations for the heptane-air mixtures. It is shown that the mixture-averaged model leads to limited errors in predicting the flame speed of planar premixed flame, but its deviation is amplified at elevated pressure, large strain rates and the intensive unsteadiness in the counterflow diffusion flame and during droplet ignition. A new strategy is proposed to obtain the RM model by emphasizing only on

critical-diffusivity-species and bundling species with similar diffusivities. The critical-diffusivity-species are verified to be species in high concentrations and some 
critical radicals by the sensitivity analysis, while the species with similar diffusivities are identified by comparing the column vectors of the diffusion matrix. The RM model is validated in different heptane-air flame configurations with an 88-species chemical mechanism, showing a good agreement with the multicomponent model by $15-20 \%$ computational time, and the cost of the RM model linearly scales with the size of chemical mechanisms.

\section{Acknowledgements}

This work was supported by the Combustion Energy Frontier Research Center, an Energy Frontier Research Center funded by the US Department of Energy, Office of Basic Energy Sciences under Award Number DESC0001198. The work at the University of Connecticut was supported by the Chemical Sciences, Geosciences and Biosciences Division, Office of Basic Energy Sciences, Office of Science, US Department of Energy under Grant DE-SC0008622. It is a pleasure to acknowledge Prof. Hai Wang for valuable discussions. 


\section{References}

[1] C.F. Curtiss, J.O. Hirschfelder, J. Chem. Phys. 17 (1949) 550-555.

[2] J.O. Hirschfelder, C.F. Curtiss, R.B. Bird, Molecular Theory of Gases and Liquids, Wiley, New York, U.S., 1954, p. 230.

[3] S. Chapman, T.G. Cowling, The Mathematical Theory of Non-Uniform Gases,

Cambridge University Press, Cambridge, U.K., 1970, p.122.

[4] K.H. Ferziger, H.G. Kaper, Mathematical Theory of Transport Processes in Gases, North-Holland, Amsterdam, N.L., 1972, p.156.

[5] W.H. Furry, Am. J. Phys. 16 (1948) 63-78.

[6] F.A. Williams, Am. J. Phys. 26 (1958) 467-469.

[7] F.A. Williams, Combustion Theory, Benjamin/Cummings, Menlo Park, U.S., 1985, Appendix E.

[8] H.K. Chellian, F.A. Williams, Combust. Sci. Technol. 51 (1987) 129-144.

[9] J. Van de Ree, Physica 36 (1967) 118-126.

[10] A. Ern, V. Giovangigli, Multicomponent Transport Algorithms, Springer-Verlag, Heidelberg, G.E., 1994, p.133.

[11] V. Giovangigli, Multicomponent Transport in Polyatomic Reactive Gas Mixtures, 27th Rarefied Gas Dynamics Conference, Asilomar Pacific Groove, AIP Conference Proceedings 1333 (2010) 635-642.

[12] S.H. Lam, Phys. Fluids 18 (2006) 073101.

[13] M.D. Smooke, Proc. Combust. Inst. 34 (2013) 65-98.

[14] A. Ern, V. Giovangigli, Combust. Theor. Model. 2 (1998) 349-372.

[15] A. Ern, V. Giovangigli, Combust. Sci. Tech. 149 (1999) 157-181.

[16] D.E. Rosner, R. S. Israel, B. L. Mantia, Combust. Flame. 123 (2000) 547-560.

[17] R.B. Dakhlia, V. Giovangigli, D. E. Rosner, Combust. Theory Modelling, 6 (2002) 1-17.

[18] H. Bongers, L.P.H. De Goey, Combust. Sci. Tech. 175 (2003) 1915-1928.

[19] V. Gopalakrishnan, J. Abraham, Combust. Flame 136 (2004) 557-566.

[20] S. Palle, R.S. Miller, Combust. Flame 151 (2007) 581-600. 
[21] J.F. Grcar, J.B. Bell, M. S. Day, Proc. Combust. Inst. 32 (2009) 1173-1180.

[22] F. Yang, C.K. Law, C.J. Sung, H.Q. Zhang, Combust. Flame 157 (2010) 192-200.

[23] Y. X. Xin, C. J. Sung, C. K. Law, Combust. Flame 159 (2012) 2345-2351.

[24] S. B. Dworkin, M. D. Smooke, V. Giovangigli, Proc. Combust. Inst. 32 (2009) 1165-1172.

[25] J. de Charentenay, A. Ern, Combust. Theor. Model. 6 (2002) 439-462.

[26] A. Kumar, S. Mazumder, Comput. Chem. Eng. 32 (2008) 1482-1493.

[27] A. Ern A, V. Giovangigli V 120 (1995) J. Comput. Phys. 105-116.

[28] A. Ern, V. Giovangigli, available at http://blanche.polytechnique.fr/www.eglib

[29] R.J. Kee, J.F. Grcar, M.D. Smooke, J.A. Miller, PREMIX: A Fortran Program for Modeling Steady Laminar One-Dimensional Premixed Flames, Report No.

SAND85-8240, Sandia National Laboratories, 1985.

[30] M. Nishioka, C.K. Law, T. Takeno, Combust. Flame 104 (1996) 328-342.

[31] Z. Chen, Studies on the Initiation, Propagation, and Extinction of Premixed Flames, Ph.D. Thesis, Princeton University, 2008.

[32] Z. Chen, M. Burke, Y. Ju, Proc. Combust. Inst. 32 (1) (2009) 1253-1260.

[33] Z. Chen, Combust. Flame 157 (2010) 2267-2276.

[34] Z. Chen, Combust. Flame 158 (2) (2011) 291-300.

[35] Z. Chen, M.P. Burke, Y. Ju, Proc. Combust. Inst. 33 (1) (2011) 1219-1226.

[36] C.S. Yoo, T.F. Lu, J.H. Chen, C.K. Law, Combust. Flame 158 (2011) $1727-1741$.

[37] H.J. Curran, P. Gaffuri, W.J. Pitz, C.K. Westbrook, Combust. Flame 114 (1998) $149-177$.

[38] W.J. Pitz, C.K. Westbrook, available at < https://www-pls.llnl.gov>

[39] A.P. Kelley, A.J. Smallbone, D.L. Zhu, C.K. Law, Proc. Combust. Inst. 33 (1) (2001) 963-970.

[40] A.J. Smallbone, W. Liu, C.K. Law, X.Q. You, H. Wang, Proc. Combust. Inst. 32 (1) (2009) 1245-1252. 
[41] J. Heywood, Internal Combustion Engine Fundamentals, McGraw-Hill, New York, U.S., 1988, p. 586.

[42] R.J. Kee, G. Dixon-Lewis, J. Warnatz, M.E. Coltrin, J.A. Miller, A Fortran Computer Code Package for the Evaluation of Gas-Phase Multicomponent Transport Properties, Report No. SAND86-8246, Sandia National Laboratories, 1986.

[43] E. Anderson, Z. Bai, C. Bischof, S. Blackford, J. Demmel, J. Dongarra, J. Du Croz, A. Greenbaum, S. Hammarling, A. McKenney, D. Sorensen, LAPACK Users' Guide, Society for Industrial and Applied Mathematics, Philadelphia, U.S., 1999. [44] T.F. Lu, C.K. Law, Combust. Flame 148 (2007) 117-126.

[45] T.P. Coffee, J.M. Heimerl, Combust. Flame 43 (1981) 273-289.

[46] H. Wang, E. Dames, B. Sirjean, D.A. Sheen, R. Tango, A. Violi, J.Y.W. Lai, F.N. Egolfopoulos, D.F. Davidson, R.K. Hanson, C.T. Bowman, C.K. Law, W. Tsang, N.P. Cernansky, D.L. Miller, R.P. Lindstedt, A high-temperature chemical kinetic model of n-alkane (up to n-dodecane), cyclohexane, and methyl-, ethyl-, n-propyl and n-butyl-cyclohexane oxidation at high temperatures, JetSurF version 2.0, September 19, 2010 (http://melchior.usc.edu/JetSurF/JetSurF2.0). 


\section{Table and Figures}

Table 1. Species with similar diffusivities identified with $\varepsilon_{G}=8 \mathrm{E}-4$.

\begin{tabular}{|c|c|c|c|c|c|}
\hline Group & Representative & & Member & species & \\
\hline \multirow[t]{3}{*}{1} & $\mathrm{C}_{7} \mathrm{H}_{15} \mathrm{O}_{2}-1$ & $\mathrm{C}_{7} \mathrm{H}_{15} \mathrm{O}_{2}-1$ & $\mathrm{C}_{7} \mathrm{H}_{15} \mathrm{O}_{2}-2$ & $\mathrm{C}_{7} \mathrm{H}_{15} \mathrm{O}_{2}-3$ & $\mathrm{C}_{7} \mathrm{H}_{15} \mathrm{O}_{2}-4$ \\
\hline & & $\mathrm{C}_{7} \mathrm{H}_{14} \mathrm{OOH} 1-3$ & $\mathrm{C}_{7} \mathrm{H}_{14} \mathrm{OOH} 2-3$ & $\mathrm{C}_{7} \mathrm{H}_{14} \mathrm{OOH} 2-4$ & $\mathrm{C}_{7} \mathrm{H}_{14} \mathrm{OOH} 3-2$ \\
\hline & & $\mathrm{C}_{7} \mathrm{H}_{14} \mathrm{OOH} 3-4$ & $\mathrm{C}_{7} \mathrm{H}_{14} \mathrm{OOH} 3-5$ & $\mathrm{C}_{7} \mathrm{H}_{14} \mathrm{OOH} 4-2$ & $\mathrm{C}_{7} \mathrm{H}_{14} \mathrm{OOH} 4-3$ \\
\hline 2 & $\mathrm{C}_{7} \mathrm{H}_{14} \mathrm{OOH} 1-3 \mathrm{O}_{2}$ & $\mathrm{C}_{7} \mathrm{H}_{14} \mathrm{OOH} 1-3 \mathrm{O}_{2}$ & $\mathrm{C}_{7} \mathrm{H}_{14} \mathrm{OOH} 4-2 \mathrm{O}_{2}$ & $\mathrm{C}_{7} \mathrm{H}_{14} \mathrm{OOH} 2-4 \mathrm{O}_{2}$ & $\mathrm{C}_{7} \mathrm{H}_{14} \mathrm{OOH} 3-5 \mathrm{O}_{2}$ \\
\hline 3 & $\mathrm{NC}_{7} \mathrm{KET} 13$ & $\mathrm{NC}_{7} \mathrm{KET} 13$ & $\mathrm{NC}_{7} \mathrm{KET} 24$ & $\mathrm{NC}_{7} \mathrm{KET} 35$ & $\mathrm{NC}_{7} \mathrm{KET} 42$ \\
\hline 4 & $\mathrm{C}_{7} \mathrm{H}_{15^{-1}}$ & $\mathrm{C}_{7} \mathrm{H}_{15}-1$ & $\mathrm{C}_{7} \mathrm{H}_{15}-2$ & $\mathrm{C}_{7} \mathrm{H}_{15}-3$ & $\mathrm{C}_{7} \mathrm{H}_{15}-4$ \\
\hline 5 & $\mathrm{CH}_{3} \mathrm{COCH}_{2}$ & $\mathrm{CH}_{3} \mathrm{COCH}_{2}$ & $\mathrm{C}_{2} \mathrm{H}_{5} \mathrm{CO}$ & $\mathrm{C}_{3} \mathrm{H}_{5} \mathrm{O}$ & \\
\hline 6 & $\mathrm{C}_{7} \mathrm{H}_{14} \mathrm{O} 1-3$ & $\mathrm{C}_{7} \mathrm{H}_{14} \mathrm{O} 1-3$ & $\mathrm{C}_{7} \mathrm{H}_{14} \mathrm{O} 2-4$ & & \\
\hline 7 & $\mathrm{C}_{7} \mathrm{H}_{14}-2$ & $\mathrm{C}_{7} \mathrm{H}_{14}-2$ & $\mathrm{C}_{7} \mathrm{H}_{14}-3$ & & \\
\hline 8 & $\mathrm{C}_{4} \mathrm{H}_{8} \mathrm{OOH} 1-3$ & $\mathrm{C} 4 \mathrm{H} 8 \mathrm{OOH} 1-3$ & $\mathrm{PC}_{4} \mathrm{H}_{9} \mathrm{O}_{2}$ & & \\
\hline 9 & $\mathrm{CH}_{3} \mathrm{CO}$ & $\mathrm{CH}_{3} \mathrm{CO}$ & $\mathrm{CH}_{2} \mathrm{CHO}$ & & \\
\hline 10 & $\mathrm{CH}_{2} \mathrm{CO}$ & $\mathrm{CH}_{2} \mathrm{CO}$ & $\mathrm{C}_{3} \mathrm{H}_{6}$ & & \\
\hline
\end{tabular}




\section{Figure Captions}

Figure 1. Relative error of the mixture-averaged model in predicting the burning flux of planar premixed heptane-air flame as a function of equivalence ratio, at pressures of 1 to $40 \mathrm{~atm}$ and freestream temperature of $300 \mathrm{~K}$.

Figure 2. The maximum temperature in the counterflow flame as a function of the strain rate, for pure heptane flowing against air at pressure of 1 to $3 \mathrm{~atm}$ and boundary temperature of $300 \mathrm{~K}$ at both inlets, calculated with different diffusion models. Dash dot line: mixture-averaged model; solid line: multicomponent model.

Figure 3. Time evolution of the maximum temperature during the ignition of heptane droplet flame (upper panel). The relative error of the mixture-averaged model in predicting the evolution of the maximum $\mathrm{H}$ radical mole fraction during the ignition of heptane droplet flame (lower panel). The inset shows a closer observation from 24 to $24.5 \mathrm{~ms}$. The simulation is conducted for a heptane droplet of initial radius of $1 \mathrm{~mm}$ and uniform temperature of $300 \mathrm{~K}$, with quiescent air at temperature of $1400 \mathrm{~K}$ and pressure of $40 \mathrm{~atm}$, calculated with different diffusion models. Dash dot line: mixture-averaged model; solid line: multicomponent model.

Figure 4. The sensitivity coefficient of the burning flux for the planar premixed flame of stoichiometric heptane-air at $40 \mathrm{~atm}$ and freestream temperature of $300 \mathrm{~K}$, with respect to the species diffusivities sorted in descending order (upper panel). And the maximum mole fraction of species presented in the order the same as the upper panel (lower panel). The simulation employs the mixture-averaged model.

Figure 5. The number of similar-diffusivity-species, with respect to the criteria on the species grouping. The analysis is conducted for the planar premixed flame and the counterflow diffusion flame. The planar premixed flame is simulated for the heptane-air mixture of the equivalence ratio 0.6 to 1.5 under 1 to $40 \mathrm{~atm}$, with the freestream temperature of $300 \mathrm{~K}$. The counterflow diffusion flame is simulated for the pure heptane following against the air under 1 to 3 atm, with the boundary temperature of $300 \mathrm{~K}$ at both inlets. The simulation employs the mixture-averaged model.

Figure 6. Relative error of various diffusion models in predicting the burning flux of the planar premixed flames for heptane-air, at equivalence ratio of 0.6 to 1.5 , pressure of 1 to $40 \mathrm{~atm}$, and freestream temperature of $300 \mathrm{~K}$. Dash-dot line: mixture-averaged model; dash line: RM model without SDS bundling; circle: RM model with bundled SDS. The RM model is composed of 10 CDS. 37 SDS are bundled into 10 groups by $\varepsilon_{G}=8 E-4$. 
Figure 7. Maximum temperature as a function of strain rate for counterflow diffusion flames of pure heptane flowing against air, at pressure of 1 to $3 \mathrm{~atm}$ and temperature of $300 \mathrm{~K}$ at both inlets, calculated with different diffusion models. Dash dot line: mixture-averaged model; solid line: multicomponent model; dash line: RM model without SDS bundling; circle: RM model with bundled SDS. The RM model is composed of 10 CDS. 37 SDS are bundled into 10 groups by $\varepsilon_{G}=8 E-4$.

Figure 8. Relative error of different diffusion models in predicting the evolution of the maximum $\mathrm{H}$ radical mole fraction during the ignition of a heptane droplet in quiescent air, with the initial droplet radius of $1 \mathrm{~mm}$, droplet temperature of $300 \mathrm{~K}$, ambient temperature of $1400 \mathrm{~K}$, and pressure of $40 \mathrm{~atm}$. Dash-dot line:

mixture-averaged model; dash line: RM model without SDS bundling; circle: RM model with bundled SDS. The RM model is composed of 10 CDS. 37 SDS are bundled into 10 groups by $\varepsilon_{G}=8 E-4$.

Figure 9. Computational time for each evaluation of the diffusion coefficients using the different diffusion models. From left to right: multicomponent model, RM model without SDS bundling, RM model with bundled SDS, mixture-averaged model. The reduced multicomponent model is composed of 10 CDS. 37 SDS are bundled into 10 groups by $\varepsilon_{G}=8 E-4$.

Figure 10. Performance of the RM model as a function of the model size. The simulation is conducted for the planar premixed flame of stoichiometric heptane-air at pressure of $40 \mathrm{~atm}$ and freestream temperature of $300 \mathrm{~K}$. For reference, the relative error is $2 \%$ and the computational time is $0.11 \mathrm{~s}$ per iteration for the mixture-averaged model. 


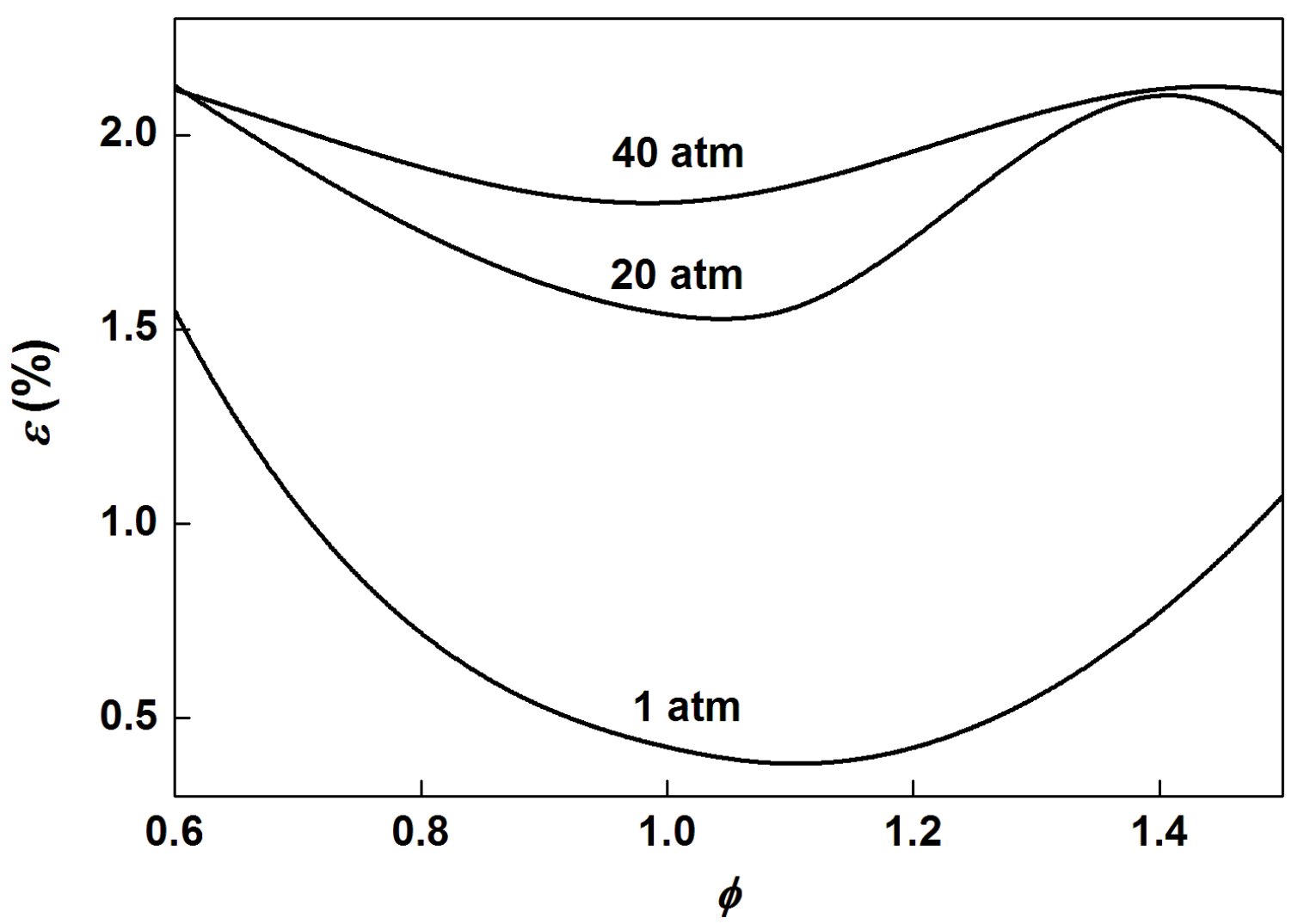

Figure 1. Relative error of the mixture-averaged model in predicting the burning flux of planar premixed heptane-air flame as a function of equivalence ratio, at pressures of 1 to $40 \mathrm{~atm}$ and freestream temperature of $300 \mathrm{~K}$. 

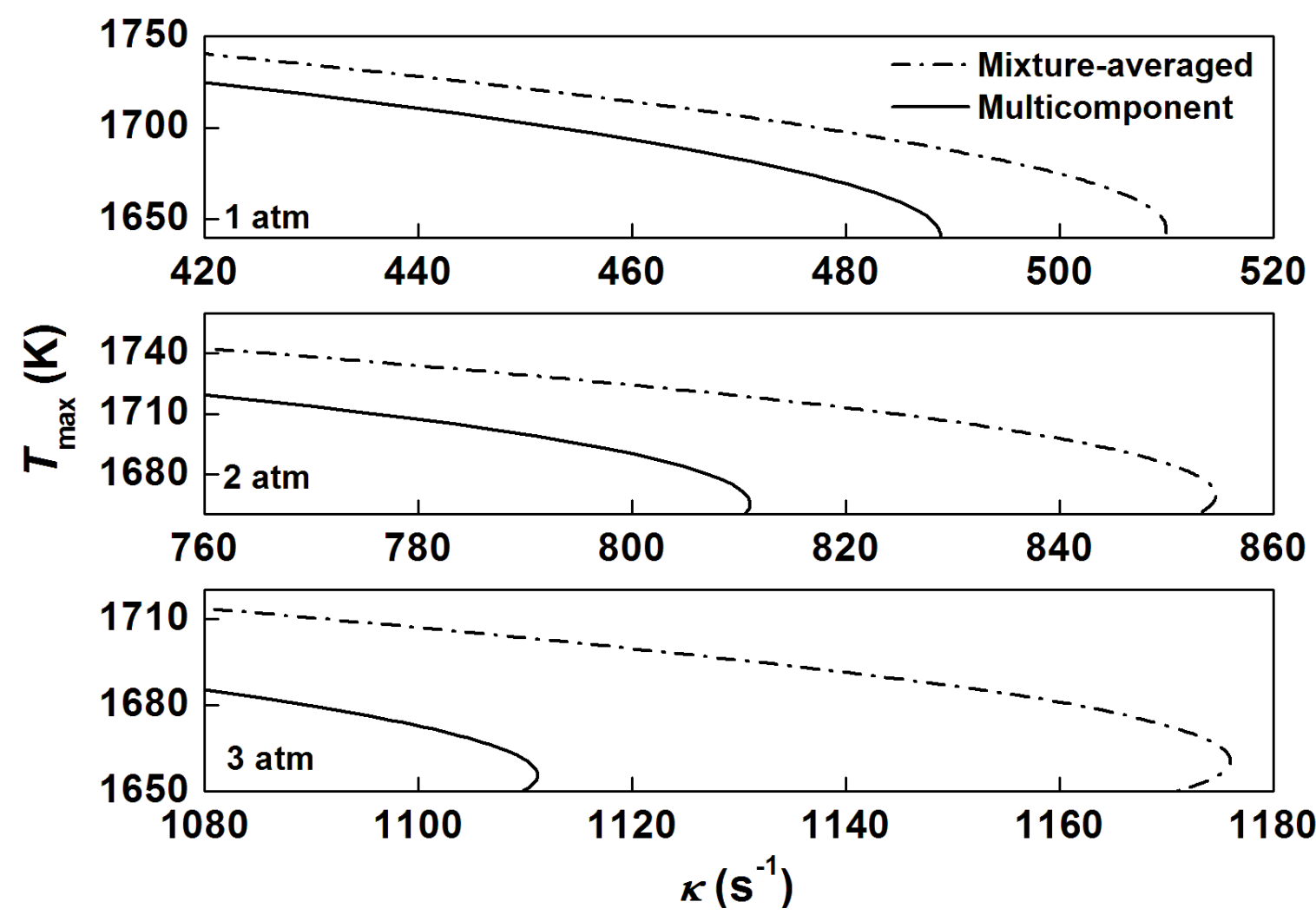

Figure 2. The maximum temperature in the counterflow flame as a function of the strain rate, for pure heptane flowing against air at pressure of 1 to $3 \mathrm{~atm}$ and boundary temperature of $300 \mathrm{~K}$ at both inlets, calculated with different diffusion models. Dash dot line: mixture-averaged model; solid line: multicomponent model. 


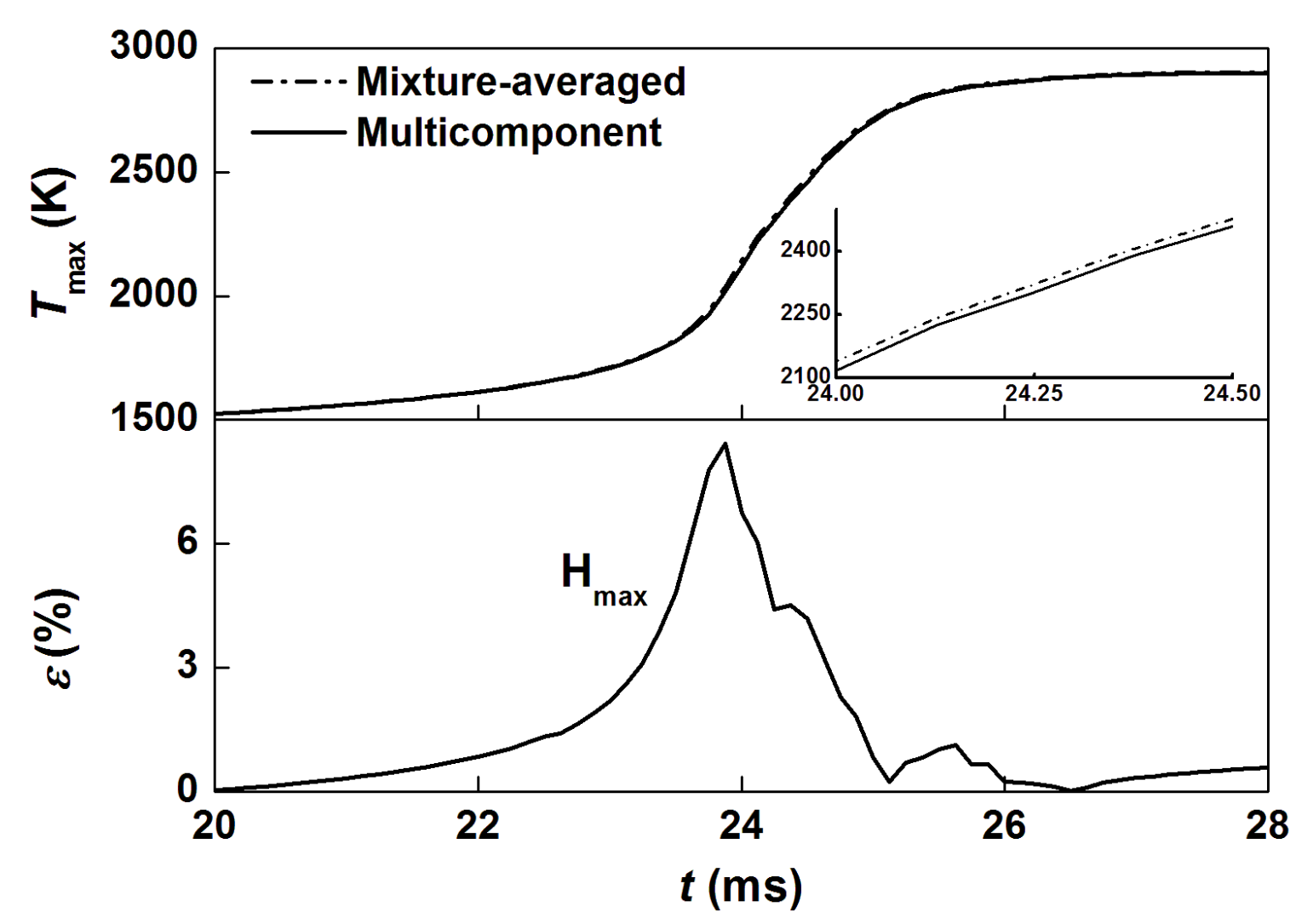

Figure 3. Time evolution of the maximum temperature during the ignition of heptane droplet flame (upper panel). The relative error of the mixture-averaged model in predicting the evolution of the maximum $\mathrm{H}$ radical mole fraction during the ignition of heptane droplet flame (lower panel). The inset shows a closer observation from 24 to $24.5 \mathrm{~ms}$. The simulation is conducted for a heptane droplet of initial radius of $1 \mathrm{~mm}$ and uniform temperature of $300 \mathrm{~K}$, with quiescent air at temperature of $1400 \mathrm{~K}$ and pressure of 40 atm, calculated with different diffusion models. Dash dot line: mixture-averaged model; solid line: multicomponent model. 


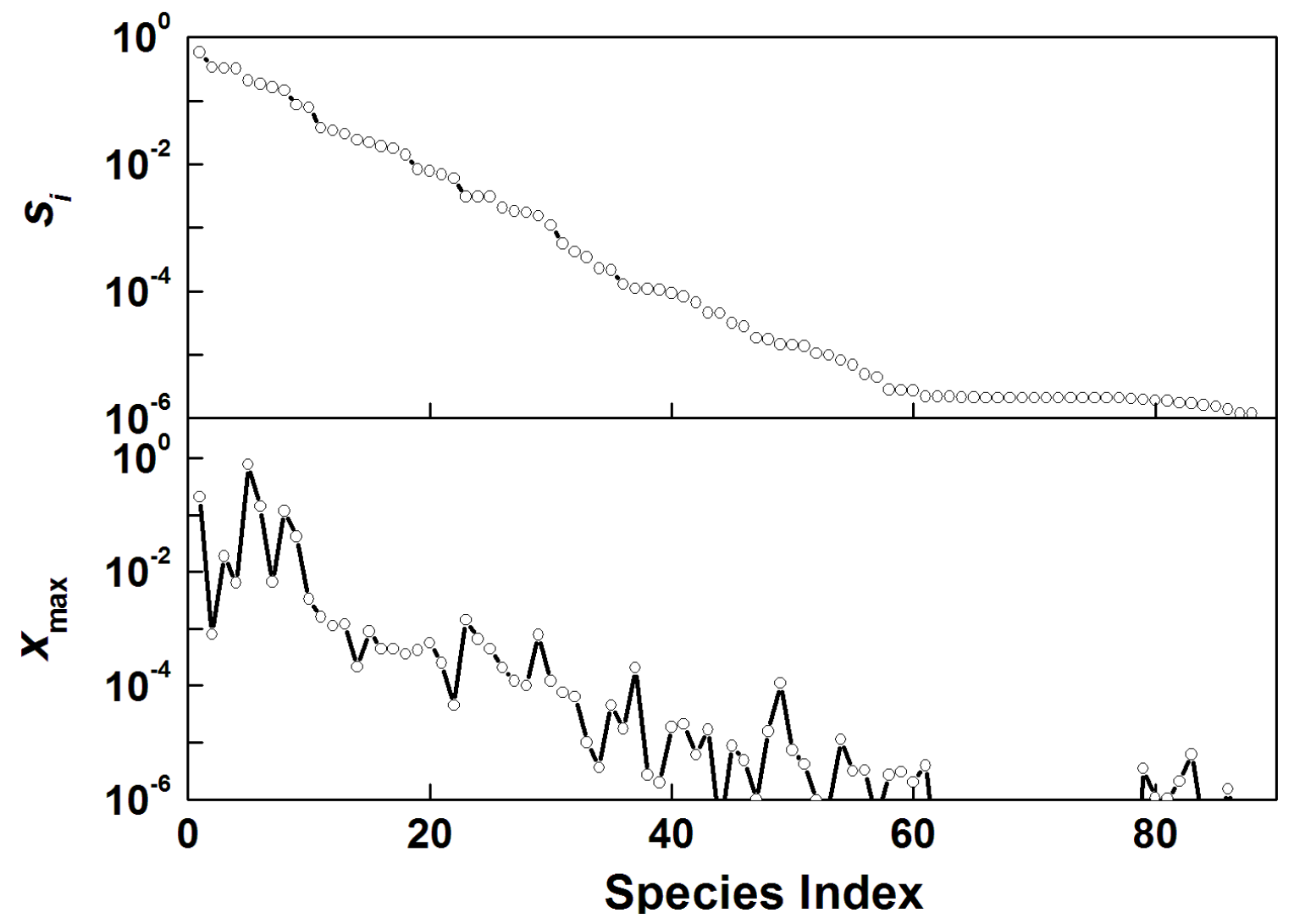

Figure 4. The sensitivity coefficient of the burning flux for the planar premixed flame of stoichiometric heptane-air at $40 \mathrm{~atm}$ and freestream temperature of $300 \mathrm{~K}$, with respect to the species diffusivities sorted in descending order (upper panel). And the maximum mole fraction of species presented in the order the same as the upper panel (lower panel). The simulation employs the mixture-averaged model. 


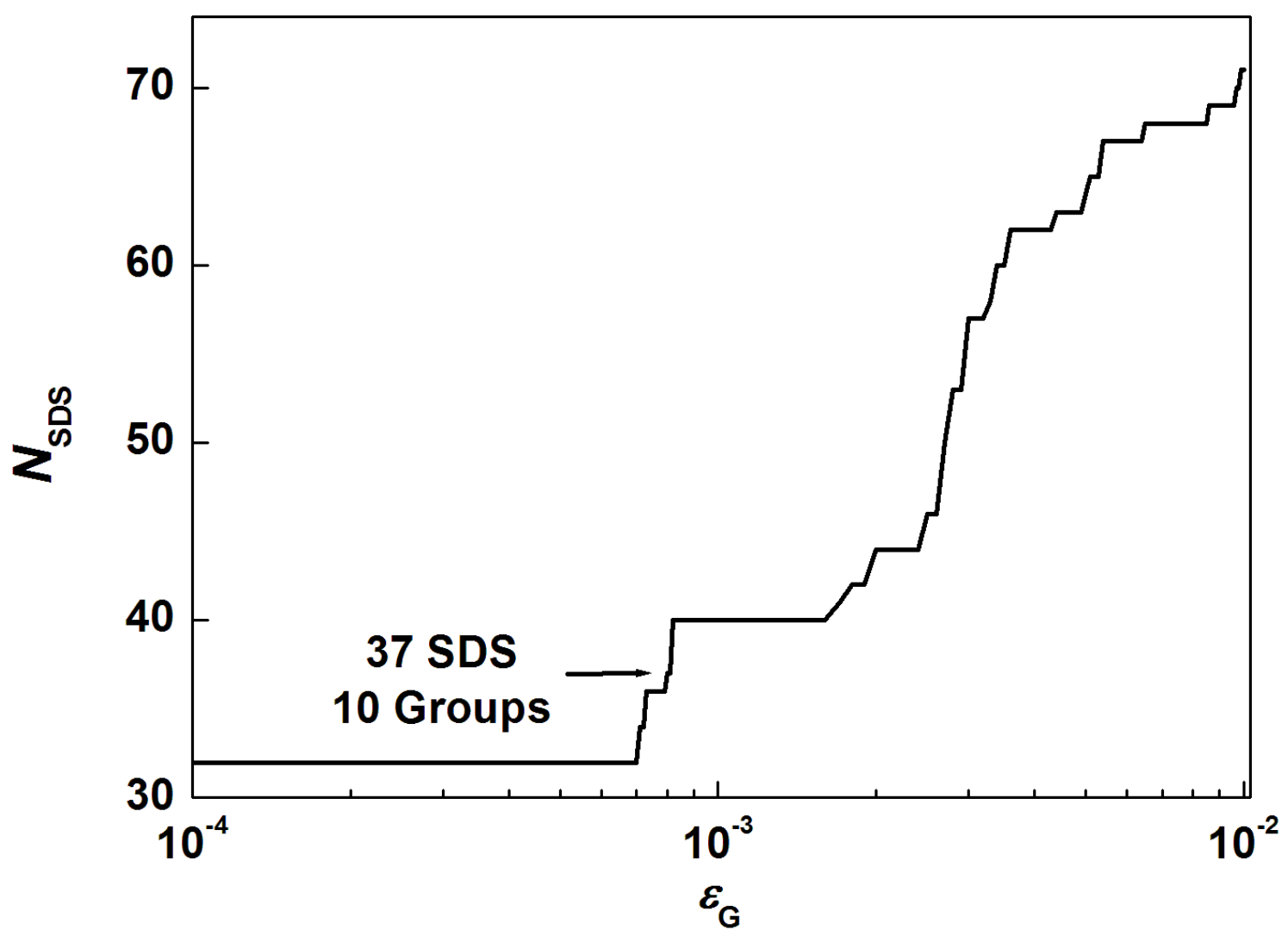

Figure 5. The number of similar-diffusivity-species, with respect to the criteria on the species grouping. The analysis is conducted for the planar premixed flame and the counterflow diffusion flame. The planar premixed flame is simulated for the heptane-air mixture of the equivalence ratio 0.6 to 1.5 under 1 to $40 \mathrm{~atm}$, with the freestream temperature of $300 \mathrm{~K}$. The counterflow diffusion flame is simulated for the pure heptane following against the air under 1 to 3 atm, with the boundary temperature of $300 \mathrm{~K}$ at both inlets. The simulation employs the mixture-averaged model. 


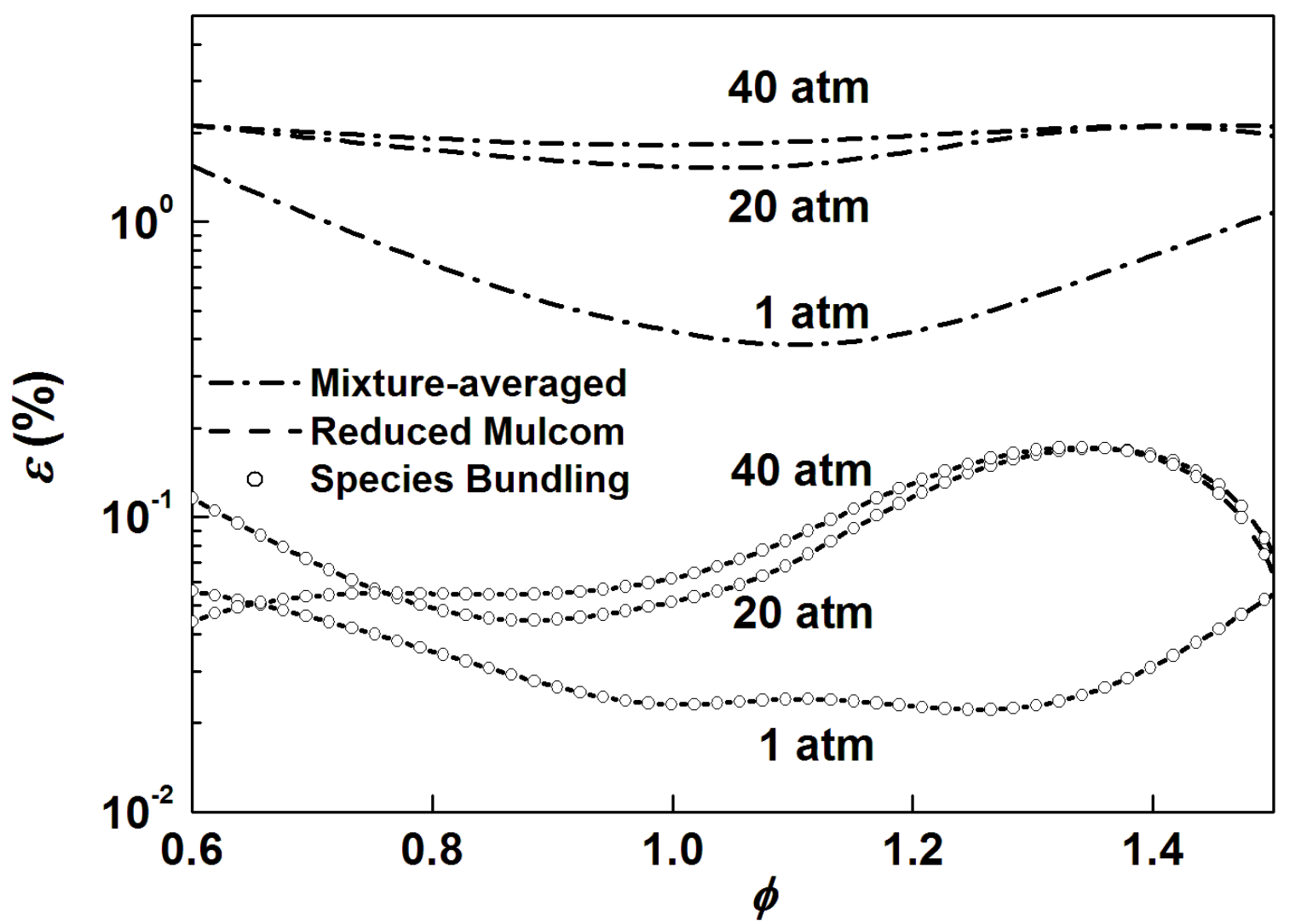

Figure 6. Relative error of various diffusion models in predicting the burning flux of the planar premixed flames for heptane-air, at equivalence ratio of 0.6 to 1.5 , pressure of 1 to $40 \mathrm{~atm}$, and freestream temperature of $300 \mathrm{~K}$. Dash-dot line: mixture-averaged model; dash line: RM model without SDS bundling; circle: RM model with bundled SDS. The RM model is composed of 10 CDS. 37 SDS are bundled into 10 groups by $\varepsilon_{G}=8 E-4$. 


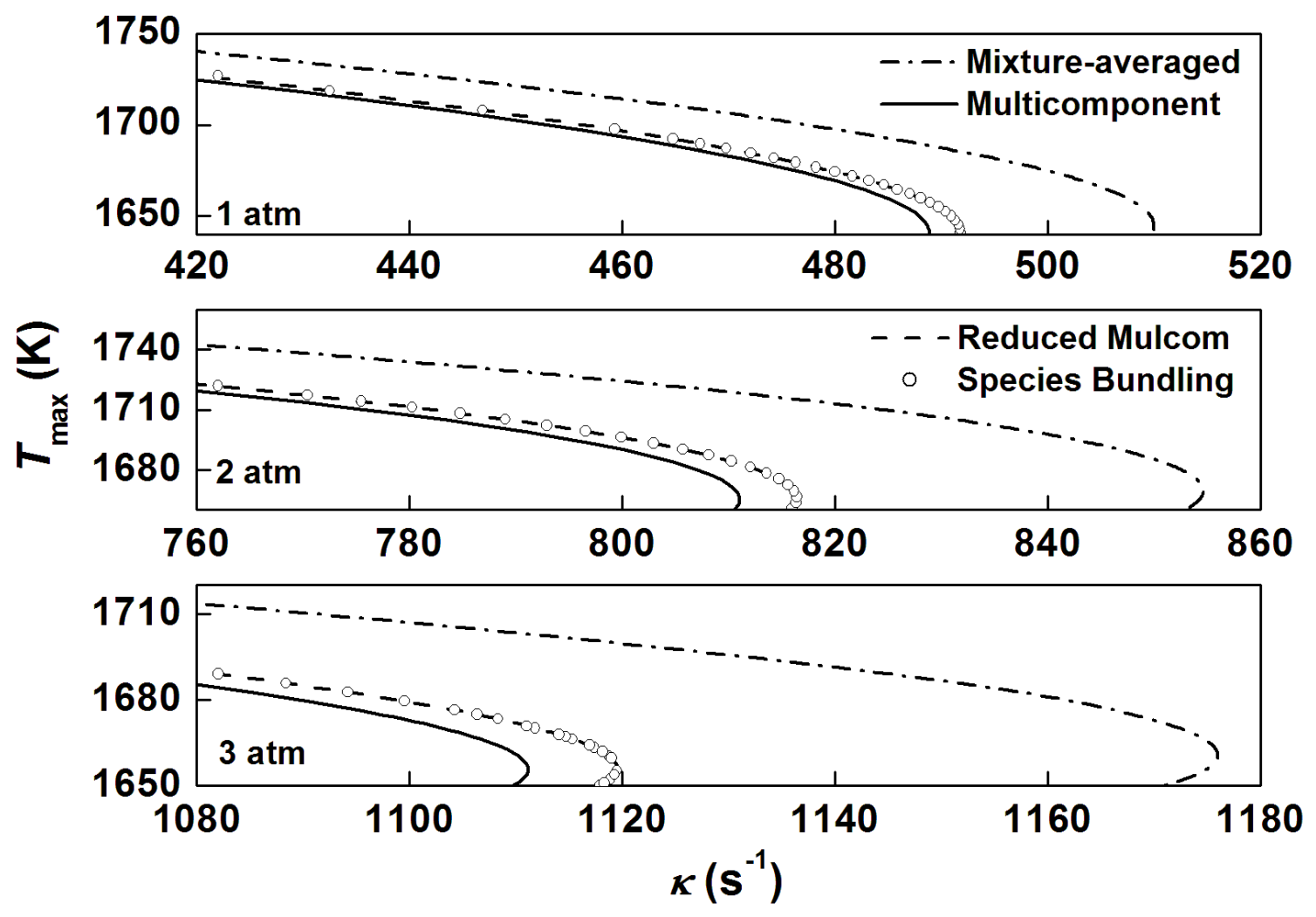

Figure 7. Maximum temperature as a function of strain rate for counterflow diffusion flames of pure heptane flowing against air, at pressure of 1 to $3 \mathrm{~atm}$ and temperature of $300 \mathrm{~K}$ at both inlets, calculated with different diffusion models. Dash dot line: mixture-averaged model; solid line: multicomponent model; dash line: RM model without SDS bundling; circle: RM model with bundled SDS. The RM model is composed of 10 CDS. 37 SDS are bundled into 10 groups by $\varepsilon_{G}=8 E-4$. 


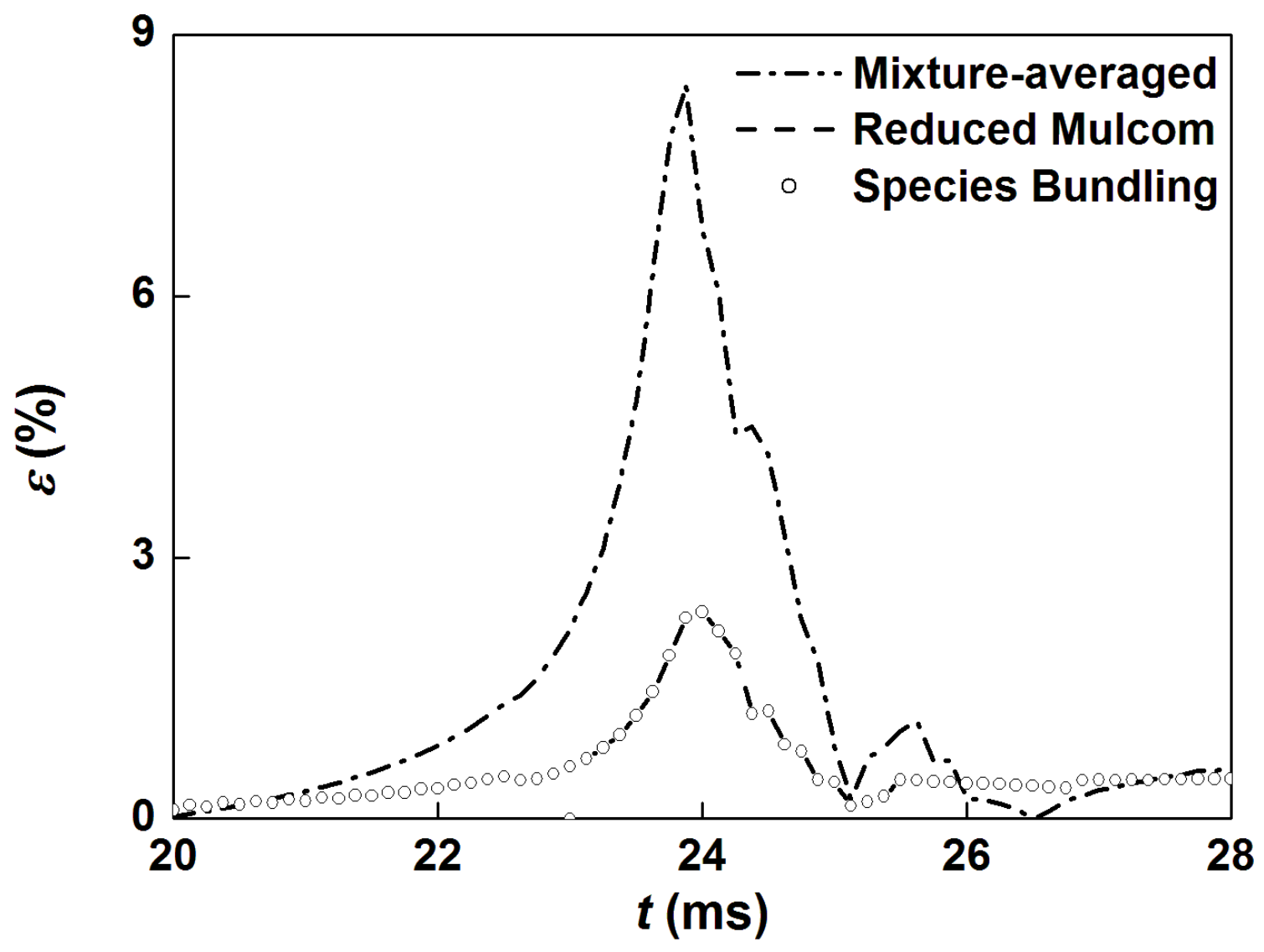

Figure 8. Relative error of different diffusion models in predicting the evolution of the maximum $\mathrm{H}$ radical mole fraction during the ignition of a heptane droplet in quiescent air, with the initial droplet radius of $1 \mathrm{~mm}$, droplet temperature of $300 \mathrm{~K}$, ambient temperature of $1400 \mathrm{~K}$, and pressure of $40 \mathrm{~atm}$. Dash-dot line:

mixture-averaged model; dash line: RM model without SDS bundling; circle: RM model with bundled SDS. The RM model is composed of 10 CDS. 37 SDS are bundled into 10 groups by $\varepsilon_{G}=8 E-4$. 


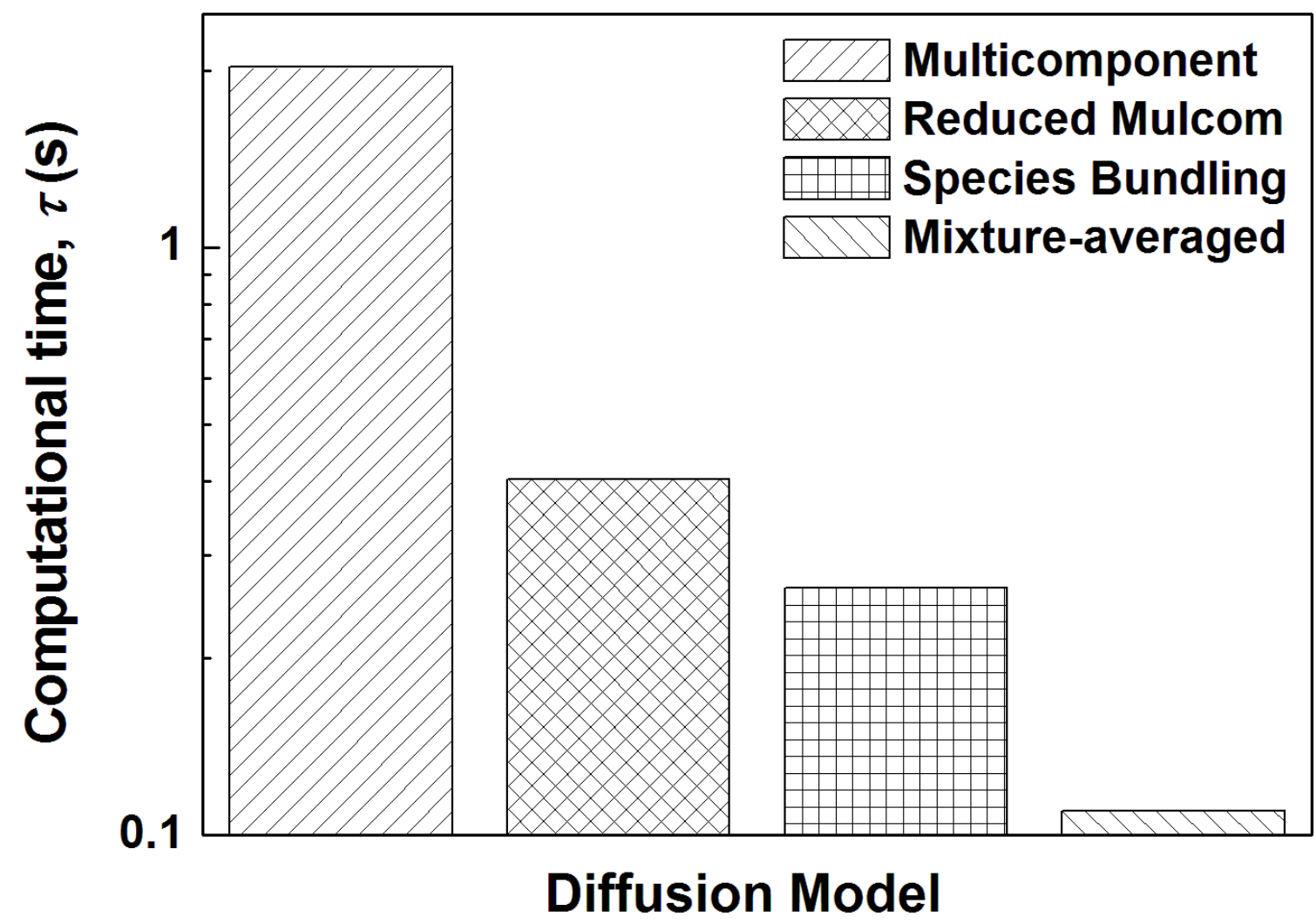

Figure 9. Computational time for each evaluation of the diffusion coefficients using the different diffusion models. From left to right: multicomponent model, RM model without SDS bundling, RM model with bundled SDS, mixture-averaged model. The reduced multicomponent model is composed of 10 CDS. 37 SDS are bundled into 10 groups by $\varepsilon_{G}=8 E-4$. 


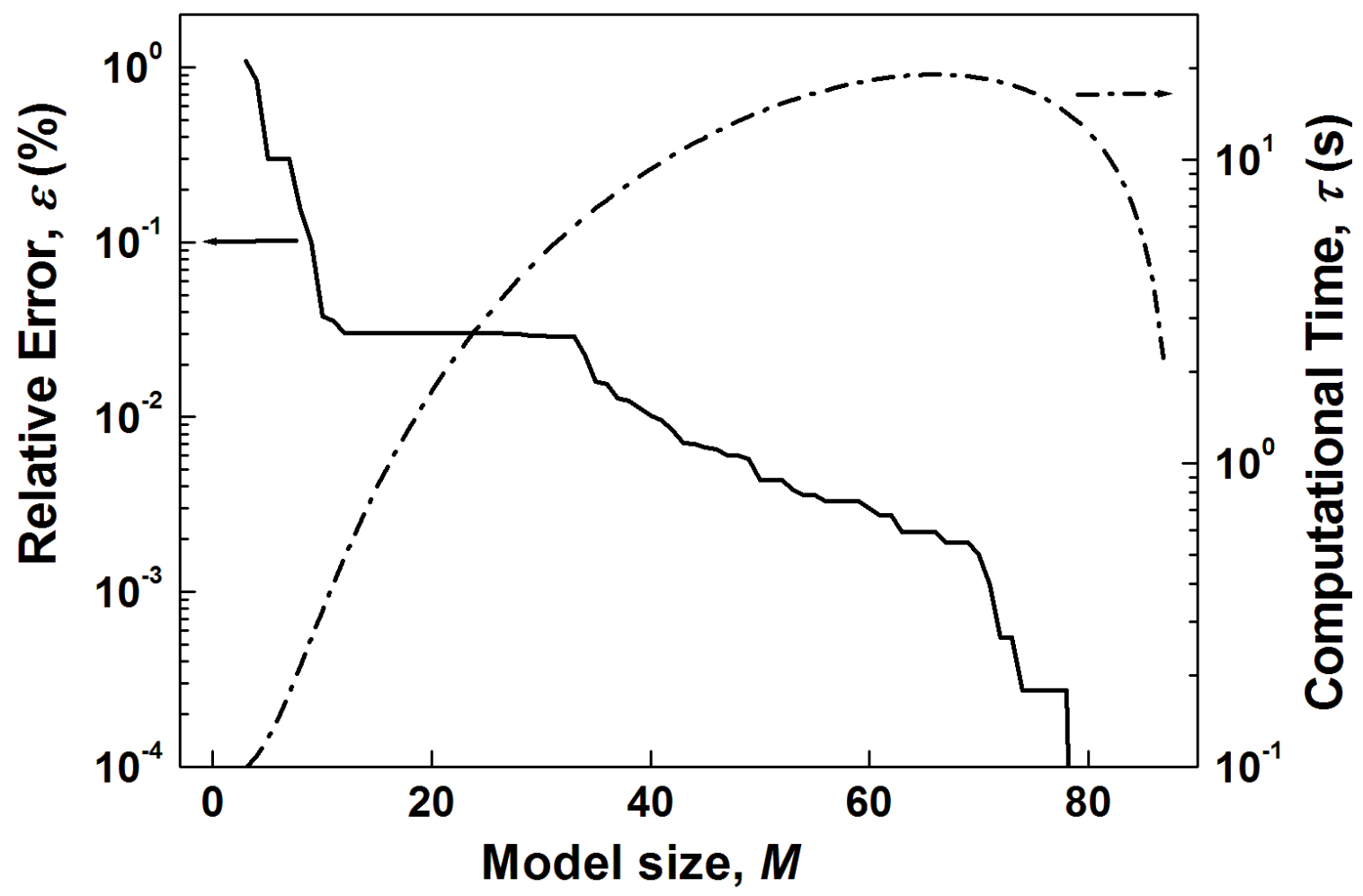

Figure 10. Performance of the RM model as a function of the model size. The simulation is conducted for the planar premixed flame of stoichiometric heptane-air at pressure of $40 \mathrm{~atm}$ and freestream temperature of $300 \mathrm{~K}$. For reference, the relative error is $2 \%$ and the computational time is $0.11 \mathrm{~s}$ per iteration for the mixture-averaged model. 